\title{
Oyster aquaculture does not impede spawning beach access for Atlantic horseshoe crabs Limulus polyphemus
}

\author{
Daphne M. Munroe ${ }^{1, *}$, Thomas M. Grothues ${ }^{2}$, Niki E. Cleary ${ }^{3}$, Joshua Daw ${ }^{1}$, \\ Samantha Estrada ${ }^{4}$
}

\author{
${ }^{1}$ Haskin Shellfish Research Laboratory, Rutgers University, 6959 Miller Ave., Port Norris, NJ 08349, USA \\ ${ }^{2}$ Department of Marine and Coastal Science, Rutgers University, 800 c/o 132 Great Bay Blvd, Tuckerton, NJ 08087, USA \\ ${ }^{3}$ Nicholas School of the Environment, Duke University, 9 Circuit Drive, Durham, NC 27710, USA \\ ${ }^{4}$ School of Natural Sciences, Fairleigh Dickinson University, 1000 River Road, Teaneck, NJ 07666, USA
}

\begin{abstract}
Farms for eastern oyster Crassostrea virginica, which are commonly located along shallow estuarine shores of the eastern USA, use a range of farm equipment and require regular access to care for and harvest oyster livestock. In some cases, these farms are located in areas used by Atlantic horseshoe crabs Limulus polyphemus as they come ashore during spring to spawn. The sandy shores of the Delaware Bay host the largest spawning aggregations of this species in the world. Limited studies have examined interactions between horseshoe crabs and intertidal oyster farms, and concern has been raised about the horseshoe crab's ability to traverse oyster farms to reach spawning habitat. This study examines potential farm interactions with horseshoe crabs in Delaware Bay during the 2018 and 2019 crab spawning season. Our studies included a range of experiments and surveys during high and low tide to observe crab abundance and behavior at rack-and-bag oyster farm and non-farm sites. In all cases, results indicated that crabs can successfully traverse rack-and-bag farms and reach spawning beaches. Crabs do not differentially use farm versus non-farm areas, and crab behavior is relatively unaltered by farm gear. These results provide important context for developing frameworks for managing ecological interactions among farms and wildlife species of concern.
\end{abstract}

KEY WORDS: Oyster - Crassostrea virginica - Horseshoe crab • Limulus polyphemus . Wildlife interactions · Movement · Shellfish

\section{INTRODUCTION}

Aquaculture is a major (and growing) component of global seafood supply (FAO 2018). With a $32 \%$ increase in value from 2012 to 2017 (USDA 2019), molluscan aquaculture continues to develop in the United States (National Marine Fisheries Service 2018). As it does, the industry faces challenges in assuring ecological and social sustainability (Billing 2018). Understanding the ways shellfish farms interact with coastal wildlife, particularly species of special concern, is paramount among those challenges

${ }^{*}$ Corresponding author: dmunroe@hsrl.rutgers.edu
(Callier et al. 2018, Barrett et al. 2019). A good understanding exists about molluscan aquaculture interactions with fundamental ecosystem processes such as particle depletion, nutrient cycling, and benthicpelagic coupling (Newell 2004, Dumbauld et al. 2009, Rose et al. 2015). Likewise, attractiveness of farm structures, such as fish net pens and shellfish farm structures, to mobile fish and crustaceans in marine habitats has been documented (Callier et al. 2018). Central to sustainability is appreciating the nature of the interaction among farms and the wildlife species that may use habitat near to or occu-

(C) The authors 2020. Open Access under Creative Commons by Attribution Licence. Use, distribution and reproduction are unrestricted. Authors and original publication must be credited. 
pied by farms (Price et al. 2017, Barrett et al. 2019), interactions that are as yet poorly studied.

Shellfish aquaculture in the Delaware Bay, Cape Shore region of New Jersey (see Fig. 1) and elsewhere has a long history as a low impact, sustainable food production system (Hilborn et al. 2018, van der Schatte Olivier et al. 2020). Oyster farms in the intertidal in Delaware Bay currently occupy approximately 4 ha (10 acres) in New Jersey and produce more than 2 million market-sized oysters annually, worth a farm-gate value of $\$ 1.37$ million USD (Calvo 2018). During the first half of the $20^{\text {th }}$ century, however, oyster farming was much more expansive; large wooden intertidal racks were used to cultivate oysters over wide stretches of this region (Ford \& Haskin 1982). The intertidal oyster farms located in this area today grow oysters using rack-and-bag cultivation, in which oysters are grown in specialized cultivation bags attached atop short metal racks (see Fig. 2a). The vast intertidal mudflats of the lower bay, with rich oyster food resources, make this a desirable location to grow high quality oysters, but it is also a region important to wildlife.

Known to be the largest horseshoe crab spawning aggregation in the world (Shuster \& Botton 1985), hundreds of thousands come ashore during the spring to mate and lay eggs along sandy beaches of Delaware Bay (Smith et al. 2002). Atlantic horseshoe crabs Limulus polyphemus are an economically, medically (Novitski 2009), and ecologically (Botton 2009) important species. Horseshoe crab blood is the source of a medical product called Limulus amoebocyte lysate (LAL) that is critical to ensuring sterility of injectable drugs, medical implements, and spacecraft, and has important global economic value (Novitski 2009). The lipid-rich eggs laid by the spawning horseshoe crabs are also an important food source for migratory shorebirds (Castro \& Myers 1993) and other estuarine species (Botton 2009). A small portion of the total Delaware Bay shoreline is, collectively, used by horseshoe crabs for spawning, is a nexus of shorebird migratory stopover habitat, and is home to intertidal oyster farming, having potential for ecologically and economically important interactions between wildlife and farming.

The overlap in both time and space of important wildlife species and oyster farm activities presents a unique opportunity to examine potential ecological interaction among wildlife and shellfish farms. Few data have been collected specifically addressing the ability of horseshoe crabs to traverse intertidal rackand-bag oyster farms to reach their spawning habitat (an exception is Munroe et al. 2017). If horseshoe crab spawning migrations are impeded by farms, it is possible that crab populations themselves may suffer, and in turn, shorebird foraging patterns and feeding opportunities may be altered. In this study, our primary goal was to characterize the interactions of horseshoe crabs transiting through farms en route to inshore spawning habitat and determine if the gear on oyster farms presents a barrier to horseshoe crabs reaching beaches to spawn. Ultimately, this information is important for wildlife species conservation as well as sustainable farm management.

\section{MATERIALS AND METHODS}

All experiments and surveys were performed during the horseshoe crab spawning season in Delaware Bay (Shuster \& Botton 1985, Smith \& Michels 2006), from May through July of 2018 and 2019, at the Rutgers University Cape Shore Laboratory and at nearby oyster farms located along the lower Delaware Bay. This area has extensive intertidal mudflats with undulating sloughs and sandbars where oyster farms are located (Fig. 1). First, experiments testing whether crabs are able to move past farm equipment were performed under control conditions in a tank in 2018, and under natural conditions within a commercial farm in 2019. Second, surveys were conducted in 2018 on the flats during each of low and high tide conditions to assess horseshoe crab abundance relative to farm footprints, and to evaluate whether crabs used intertidal habitats differently where farm gear was present.

\subsection{Horseshoe crab movement: tank experiment}

To observe horseshoe crab movement around racks, a large fiberglass tank $(3.7 \mathrm{~m}$ long $\times 1.5 \mathrm{~m}$ wide $\times$ $0.51 \mathrm{~m}$ deep) was filled with filtered bay water to a depth of $30 \mathrm{~cm}$. Live horseshoe crabs were collected by hand from the adjacent Cape Shore mudflats for use in the experiments. Experiments began 9 May 2018 and continued through 21 June 2018, during the spawning season for horseshoe crabs; thus, all animals used in the experiment were actively coming ashore to spawn and were assumed to be mature, although maturity was not confirmed with presence of genital slits or pores. A total of 20 horseshoe crabs, collected at random, were used for each experimental trial. Before being placed into the tank, each crab was measured (widest distance across the prosoma) and sexed, then assigned an identification number that was written on both sides of the prosoma using a 

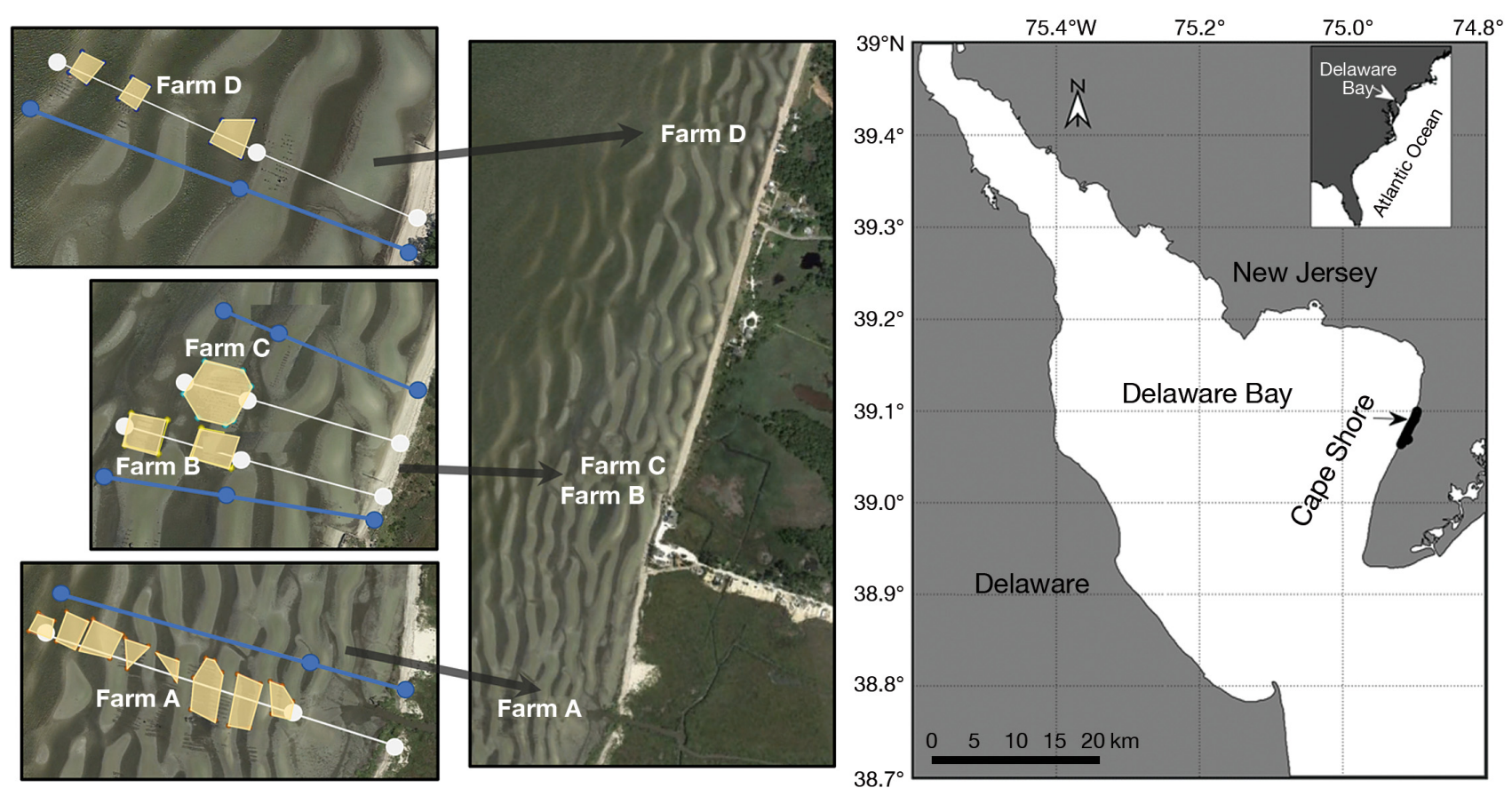

Fig. 1. Survey transects at 4 oyster farms, shown overlain on Google ${ }^{\circledR}$ map satellite image to illustrate habitat during low tide (note that images are not from the same year as the transect survey was performed, so some features may differ slightly). Shaded yellow blocks on each farm: locations of farm rack-and-bag gear in 2018. Blue: control transects; white: farm transects (see Table 1 for location details). Map on right: Cape Shore in the Delaware Bay; center map: layout of farms relative to one another

yellow wax pencil (this mark was not permanent and was gently rubbed off with a rag before returning crabs to the bay after the experiment). The size, sex, and identification number of each crab was recorded, and marked animals were placed into the tank and allowed to acclimate for $15 \mathrm{~min}$ before the start of the experiment. During the acclimation period, many animals engaged in amplexus.
A total of 11 treatments were tested. Treatments included a control, in which the footprint of an oyster rack was drawn on the tank bottom but no physical structure was put in the tank, and 10 farm gear treatments of varying heights and configurations. The suite of treatment types (Fig. 2b) included 3 rack heights $(7.5,12.5$, and $20.5 \mathrm{~cm}$ above the bottom; the full field rack height of $30.5 \mathrm{~cm}$ was not used because

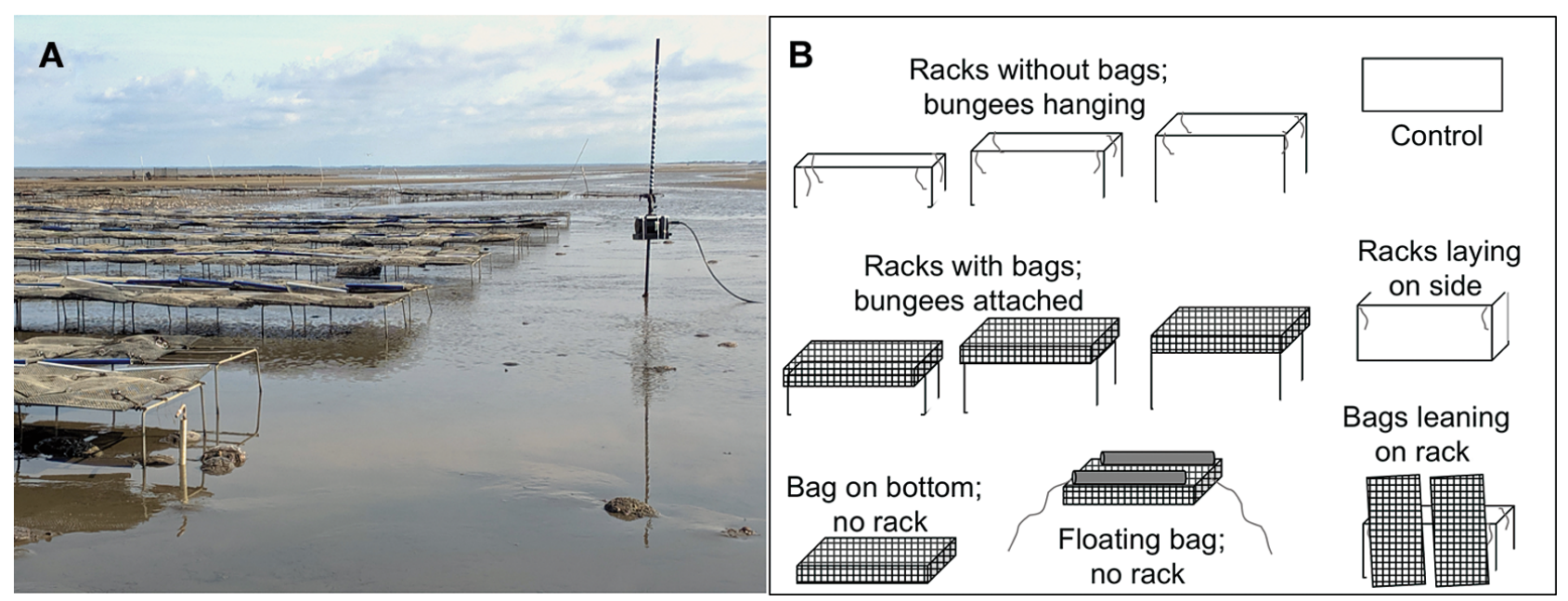

Fig. 2. (A) Example of typical oyster farm rack-and-bag gear, with dual-frequency identification sonar mounted on a pole and aimed at farm. Photo taken during low tide on 11 May 2019. Note horseshoe crabs visible beneath and around farm racks. (B) Illustrations of the 10 farm gear treatment configurations used in tank experiments, plus the control 
the depth of the water in the tank was lower, placing the full height racks above the water), with and without oyster bags attached, an oyster bag on the bottom of the tank (no rack), a floating oyster bag tethered to the bottom with $0.63 \mathrm{~cm}\left(1 / 4^{\prime}\right)$ braided sinking line, oyster bags leaning on the side of a rack, and a rack on its side (no bag). Racks used were rebar racks that are used by farmers, had elastic cords with metal hooks attached (farmers use these to hold bags onto the racks), and bags were high density polyethylene mesh (typical of that used on farms) containing oyster shells to mimic adult oysters. The designated treatment structure was placed in the tank with 20 horseshoe crabs and a timer started. The crabs were observed continuously for $15 \mathrm{~min}$ as they moved about the tank and interacted with the treatment structures. A note was recorded for every horseshoe crab each time that individual passed to the side, beneath, or over a structure. This 15 min observation period was considered one replicate for a given treatment. Each treatment type was replicated a minimum of 9, and maximum of 14 times (uneven replication was due to time limitations for the experiment), for a total of 139 independent trials. Frequency of behavior (around, under, over) observed for all combinations of gear type and crab category (male, female, or amplexus) were analyzed using log-linear multidimensional contingency analysis to test for independence among levels (analysis performed in RStudio v.1.1.453, using VCD v.1.4-4; Meyer et al. 2017).

\subsection{Horseshoe crab movement: natural conditions}

Due to the high turbidity of Delaware Bay (McSweeney et al. 2017), we used specialized underwater sonar video technology (dual-frequency identification sonar, DIDSON; Sound Metrics Corps) mounted on a pole at a height of $1 \mathrm{~m}$ above the bottom to view and record horseshoe crabs moving across the mudflats at farm and control stations (Fig. 2a). DIDSON provides real-time nearly videoquality observation of marine habitats and animals when conditions such as low light or high turbidity prevent visual observation (Able et al. 2014). Two sonars were used concurrently to collect paired video of the bottom at 2 locations equidistant from the high tide line and at the inshore edge of the farm ( $91 \mathrm{~m}$ from the high tide line). The sonars were tethered by a $100 \mathrm{~m}$ cable to land, where each was connected to power and a computer on which the feed could be viewed and recorded. This setup allowed the sonars to be remotely turned on and off. In total, 7 high tide events occurring between 13 and 23 May 2019 were observed and recorded, including $\sim 5.8 \mathrm{~h}$ of sonar video from each sonar unit on each tide event of horseshoe crabs moving across the bottom at a 'control' location that had no farm gear, and a second 'farm' location that was within a commercial farm with rack-and-bag oyster gear. The duration of sonar recording time varied slightly from one tide to the next, as recording began as the tide submerged both units, and ended when the tide dropped below the units. For the duration of the experiments, water temperature and direction and velocity of tidal currents were continuously measured and recorded using a tilt current sensor (TCM-4; Lowell Instruments).

Racks were positioned $30.5 \mathrm{~cm}\left(12^{\prime}\right)$ above the bottom (this height is a regulated requirement intended to prevent interference with crab movement) and held oyster bags containing oysters attached to the top (racks and bags are as described in Section 2.1). Because sonars were fixed, sonar resolution allowed observers to see horseshoe crabs approaching and moving below or over the gear. A number of evaluators were used to make paired concurrent counts of crabs from DIDSON sonars. To verify agreement among individual evaluators, 6 evaluators independently counted the same 5 randomly selected, $10 \mathrm{~min}$ segments of recorded sonar video. Their counts of the same 5 video segments were used to estimate interrater reliability using an intraclass correlation coefficient (ICC) with a 2-way random effect for absolute agreement model with multiple raters (Koo \& Li 2016). Both sonars were set to view the same bottom footprint (approximately $15 \mathrm{~m}^{2}$ ) and faced the same cardinal direction $\left(260^{\circ} \mathrm{W}\right)$. The sonar feeds were viewed in real time on computers attached to each unit. Paired counts of single horseshoe crabs and pairs in amplexus from each sonar were made every $0.5 \mathrm{~h}$ for a duration of $10 \mathrm{~min}$ each, during each of the 7 high tide events. Paired concurrent counts from control and farm bottom were non-normally distributed; therefore, a non-parametric Wilcoxon signed rank was used to test the null hypothesis that there is no difference in the number of horseshoe crabs moving through control versus farmed bottom.

Recorded videos of control and $30.5 \mathrm{~cm}\left(12^{\prime}\right)$ high racks from 6 replicate high tide events (1 of the 7 recorded did not have sufficient resolution to track fine-scale movement) were further analyzed using Tracker Video Analysis software v.5.1.2 (https:// physlets.org/tracker/) to collect horseshoe crab movement data. Specifically, the speed, direction, and path efficiency (straightness, calculated as the ratio of net to gross distance traveled; NGDR) of indi- 
vidual single and amplexus pair crabs moving through the field of view were measured. A $10 \mathrm{~min}$ video segment at $2 \mathrm{~h}$ prior to high tide (early flood), $1 \mathrm{~h}$ prior to high tide (flood), during high tide (slack high), $1 \mathrm{~h}$ after high tide (early ebb), and $2 \mathrm{~h}$ after high tide (ebb) were used for analysis to allow testing for changes in behavior during the course of a tide cycle. For each paired 10 min video segment, the paths of a minimum of 8 single crabs and 4 amplexus pairs were measured, then averaged to generate the path characteristics (speed, direction, and path efficiency) for that 10 min video. Paired control and farm observations were analyzed using MANOVA to compare differences in crab movement over farm versus control bottom, and among tide stages. This approach challenged the null hypotheses that there was no difference in horseshoe crab movement patterns on control versus farmed bottom, and that movement does not change with tide stage.

\subsection{Horseshoe crab survey: low tide}

Abundance surveys were conducted at low tide using paired transects, laid out and marked on 4 intertidal farms in the Cape Shore region of Delaware Bay (Fig. 1). At each farm, paired transects (1 $\mathrm{m}$ wide) were oriented perpendicular to the shore with one transect intersecting an oyster farm (Table 1), and a parallel control transect passing through adjacent unfarmed intertidal habitat, following methods described in Munroe et al. (2017). Each transect was categorized into 2 zones. The zone inshore of the oyster farms was the distance inshore of the farm equipment and was approximately $100 \mathrm{~m}$ in length, and the within-farm zone encompassed the distance of each farm (the equivalent farm distance was used for the length of this zone at the control pair), which varied among farms (Table 1, Fig. 1). During daytime low tides, starting on 8 May 2018 and continuing through 25 June 2018, transects on all 4 farms were walked and all horseshoe crabs encountered along each transect were counted, and their location (inshore of, or within-farm) was noted. Walks were repeated a minimum of weekly, for a total of 9 repeated surveys during the 2018 spawning season. A Kruskal-Wallis test challenged the null hypothesis that there was no difference in the number of horseshoe crabs observed inshore and within farm gear among paired farm and control transects during low tide.

\subsection{Horseshoe crab survey: high tide}

Paired transects at 2 of the 4 farms were also observed during high tide events between 28 May and 2 June 2018 using DIDSON sonar mounted to the front of a small aluminum boat. Sonar video was recorded as the boat moved slowly $\left(\sim 0.74 \mathrm{~m} \mathrm{~s}^{-1}\right)$ under the power of a small electric trolling motor along transects set in paired oyster farm and control habitats, as described in Section 2.3 for the low tide surveys. The sonar was connected to batteries, a control unit, and computer in the boat. Sonar video was viewed in real time on a computer on the boat, and video was recorded concurrently with the GPS location of the boat. Data collection was largely limited to farms B and C (Fig. 1) because of logistical difficulty in reaching all 4 farms during a single high tide, due to limitations of the battery and the necessarily slow speed of the boat. Counts of the number of single horseshoe crabs and pairs in amplexus along the transects were made from videos recorded on 6 replicate high tide events. In some cases, oyster bags on the racks obscured the ability of the sonar to see the entire bay floor; therefore, video taken along farm segments of transects was corrected for area obscured. A correction factor was calculated by randomly selecting 25 still frames from each video segment and estimating the area visually blocked in each frame by farm gear. The average area obscured for each video segment was used to scale the horseshoe crab counts from that segment, assuming an even distribution of horseshoe crabs. A Kruskal-Wallis test challenged the null hypothesis that there is no difference in the number of horseshoe crabs observed

Table 1. Locations and lengths of transect zones to monitor horseshoe crabs on each oyster farm (see Fig. 1 for farm locations)

\begin{tabular}{|c|c|c|c|c|c|}
\hline \multirow{2}{*}{ Farm } & \multicolumn{3}{|c|}{ Latitude / longitude } & \multirow{2}{*}{$\begin{array}{l}\text { Inshore zone } \\
\text { distance }(\mathrm{m})\end{array}$} & \multirow{2}{*}{$\begin{array}{c}\text { Farm zone } \\
\text { distance }(\mathrm{m})\end{array}$} \\
\hline & High tide edge & Inshore edge of farm gear & Offshore edge of farm gear & & \\
\hline A & $39.07034^{\circ} \mathrm{N}, 74.91412^{\circ} \mathrm{W}$ & $39.07082^{\circ} \mathrm{N}, 74.91525^{\circ} \mathrm{W}$ & $39.07199^{\circ} \mathrm{N}, 74.91818^{\circ} \mathrm{W}$ & 112 & 287 \\
\hline $\mathrm{B}$ & $39.07442^{\circ} \mathrm{N}, 74.91185^{\circ} \mathrm{W}$ & $39.07476^{\circ} \mathrm{N}, 74.91302^{\circ} \mathrm{W}$ & $39.07505^{\circ} \mathrm{N}, 74.91399^{\circ} \mathrm{W}$ & 108 & 91 \\
\hline $\mathrm{C}$ & $39.07478^{\circ} \mathrm{N}, 74.91163^{\circ} \mathrm{W}$ & $39.07520^{\circ} \mathrm{N}, 74.91295^{\circ} \mathrm{W}$ & $39.07536^{\circ} \mathrm{N}, 74.91348^{\circ} \mathrm{W}$ & 123 & 51 \\
\hline $\mathrm{D}$ & $39.08045^{\circ} \mathrm{N}, 74.90810^{\circ} \mathrm{W}$ & $39.08080^{\circ} \mathrm{N}, 74.90905^{\circ} \mathrm{W}$ & $39.08131^{\circ} \mathrm{N}, 74.91035^{\circ} \mathrm{W}$ & 92 & 126 \\
\hline
\end{tabular}


inshore and within farm gear among paired farm and control transects during high tide, using both uncorrected and corrected counts.

\section{RESULTS}

\subsection{Horseshoe crab movement: tank experiment}

In total, 330 male and 129 female horseshoe crabs were used in the tank experimental trials. Horseshoe crabs ranged in size from 16 to $28 \mathrm{~cm}$ prosoma width for males (mean $\pm \mathrm{SD}$ : $20.1 \pm 1.6 \mathrm{~cm}$ ) and from 21 to $30.5 \mathrm{~cm}$ for females $(25.8 \pm 2.1 \mathrm{~cm})$. Across all $11 \mathrm{rack}$ treatments tested, all categories of crabs (single males, single females, pairs in amplexus) were observed moving around and under/over/through the farm gear treatment, including single females and crabs engaged in amplexus, successfully passing under and over the 2 shortest rack heights. None of the 128 trials involving oyster racks or oyster bags (i.e. all non-control treatments) resulted in a crab being trapped or impeded from moving past or through the oyster gear.

Behavior in the tank experiment varied among some gear types $\left(\chi_{60}^{2}=540, \mathrm{n}=3032, \mathrm{p} \ll 0.0001\right)$, with more horseshoe crabs passing over the shortest rack heights and under the large and medium racks than expected if behavior were completely random and fewer going under the shortest racks. In other cases, horseshoe crabs did not behave differently than expected at random.

\subsection{Horseshoe crab movement: natural conditions}

Horseshoe crab movement patterns varied on farms compared to controls, and among tide conditions. Path straightness on average was $3 \%$ lower at farms $\left(F_{1,615}=16.1, \mathrm{p}<0.0001\right)$ than at control locations, and path direction differed among flood and ebb conditions $\left(F_{1,615}=39.8, \mathrm{p}<0.0001\right)$ (Fig. 3$)$. Thus, we rejected the null hypothesis of no difference in horseshoe crab movement patterns on farmed versus unfarmed bottom. Velocity, net distance, and gross distance of horseshoe crab movement were not affected by oyster farms or tidal conditions. On average, single horseshoe crabs moved with a velocity of (mean $\pm \mathrm{SD}$ ) $13.8 \pm 7.7 \mathrm{~cm} \mathrm{~s}^{-1}$ at farm habitats and $13.6 \pm 7.5 \mathrm{~cm} \mathrm{~s}^{-1}$ at control habitats, and pairs in amplexus moved $13.8 \pm 7.7 \mathrm{~cm} \mathrm{~s}^{-1}$ at farm habitats and $13.4 \pm 7.2 \mathrm{~cm} \mathrm{~s}^{-1}$. Overall, movement behavior to and from inshore spawning habitat was not affected by farms, and path direction showed horseshoe crabs moving towards the shore during flood tide, and moving away from the shore during ebb tide, with their direction following to tidal currents.

When counting single horseshoe crabs using polemounted sonar video at farms, our raters had excellent reliability with $\mathrm{ICC}=0.95$ (95\% CI: $0.83<\mathrm{ICC}<0.99)$.
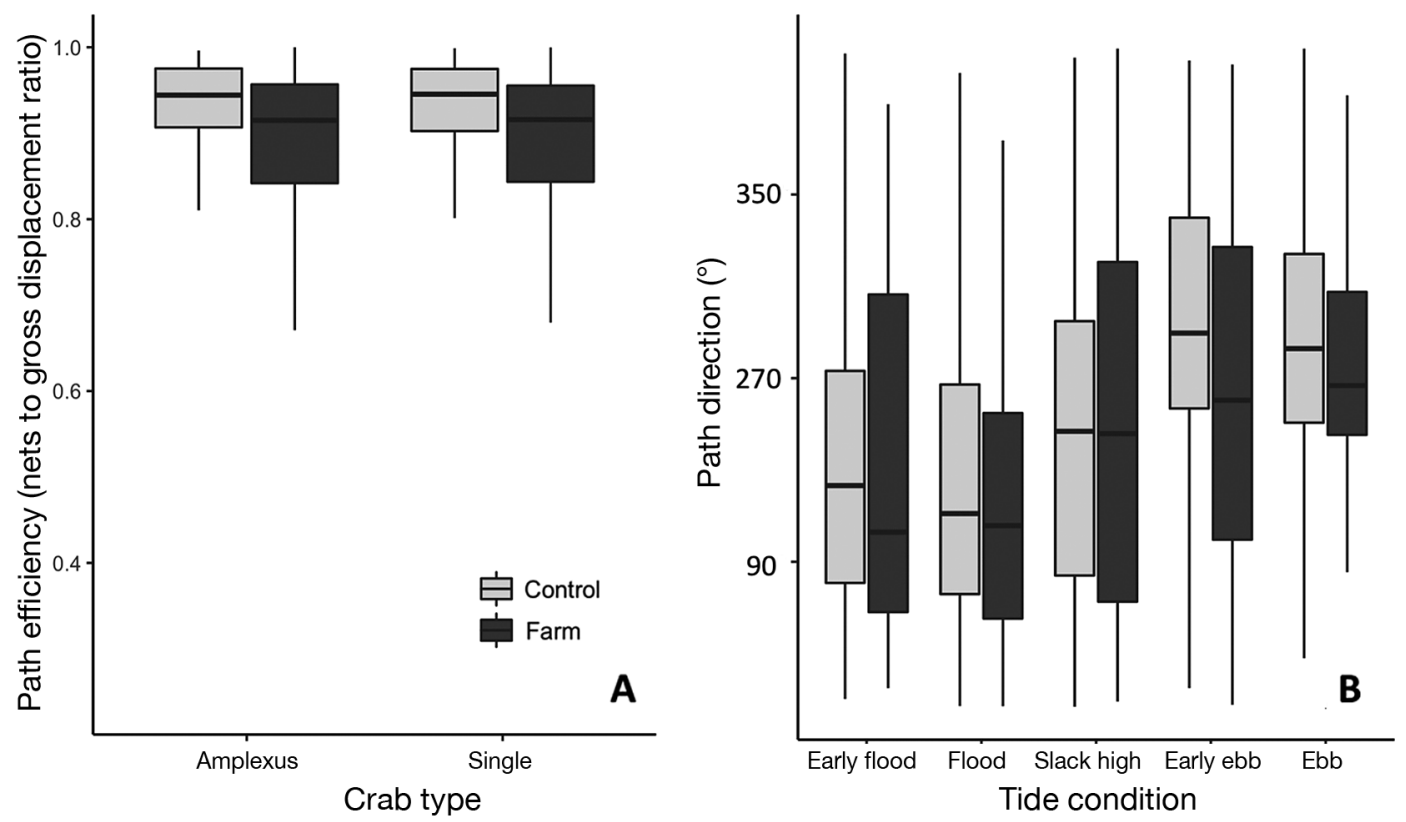

Fig. 3. Boxplots of (A) path straightness (net to gross displacement ratio) of single horseshoe crabs and pairs in amplexus moving through oyster farms and controls (with no obstacles) and (B) net direction of horseshoe crab movement (in cardinal degrees) by tide stage in farms and controls 


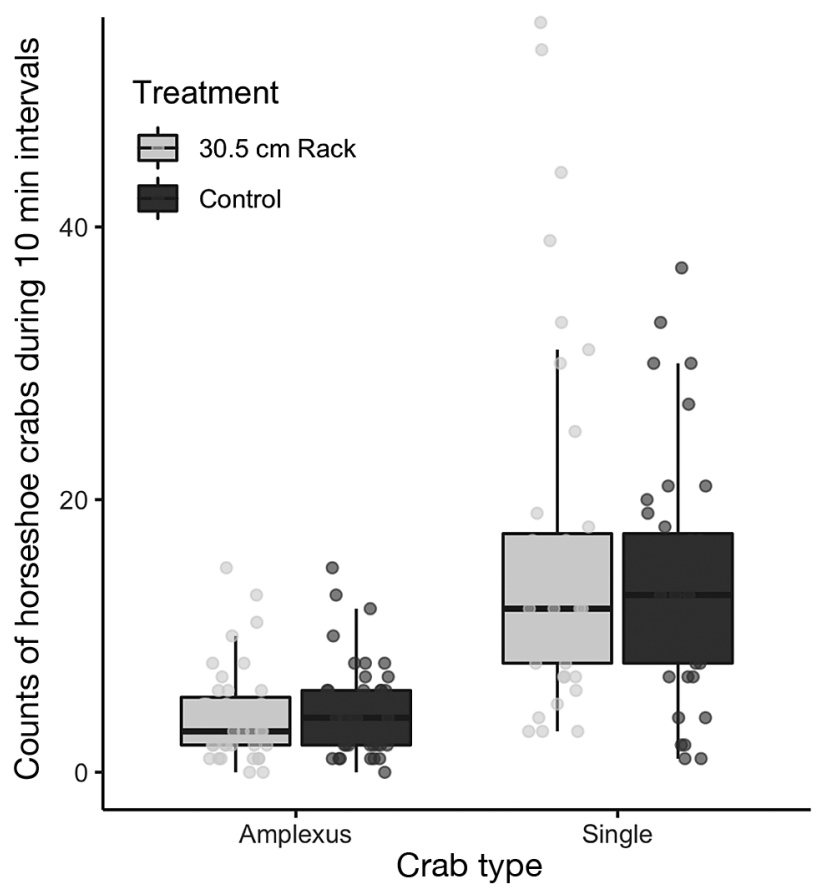

Fig. 4. Box plots (overlaid with raw observations in transparent circles, jittered to allow independent observations to be seen) of the counts of horseshoe crabs during $10 \mathrm{~min}$ intervals at control and $30.5 \mathrm{~cm}$ racks
0.45) crabs (Fig. 4). This result was observed for all tide stages and we accept the null hypothesis of no difference in the number of horseshoe crabs moving through farmed versus control bottom. See Videos S1 \& S2 in the Supplement at www.int-res.com/articles/suppl/ q012p081_supp/ for examples of horseshoe crabs moving under racks at low tide, as viewed with sonar.

\subsection{Horseshoe crab survey: low tide}

Numbers of horseshoe crabs observed during the low tide transect surveys varied through the spawning season and among farms (Fig. 5). Counts ranged from a low of zero at the beginning and end of the observation period to a high of 135 transect $^{-1}$ during the observation made on 21 May 2018; this period fell between the new and full moon in late May of that year. In total, over all transects and across the entire observation period, 1176 crabs were observed on the 4 farms, none of which were impinged by farm gear. No difference was found among the number of horseshoe crabs counted at habitat inshore of farm gear compared to controls $(p=0.73)$. Likewise, no difference was found in the number of crabs counted
When counting pairs in amplexus, our raters had good reliability with $\mathrm{ICC}=0.92(95 \% \mathrm{CI}: 0.76<\mathrm{ICC}<$ 0.99). Number of horseshoe crabs observed in paired 10 min DIDSON video segments ranged from 0 to 55 single horseshoe crabs (mean $\pm \mathrm{SD}=$ $10.7 \pm 8.2$, median $=9$ ), and 0 to 15 amplexus pairs $(2.7 \pm 2.7,2)$. No difference was detected between the number of crabs transiting control (non-farm) bottom versus bottom with rack-and-bag farm gear with a clearance of $30.5 \mathrm{~cm}$ above the bottom for both single $(Z=0.03, \mathrm{p}=$ 0.69) and amplexus $(Z=0.07, \mathrm{p}=$

Fig. 5. Numbers of horseshoe crabs counted along transects during low tide. (A) Counts from habitat inshore of oyster farms; (B) habitat within the farm footprint. Shades of lines and points are paired transects at each farm; solid lines: counts from the control transect; dashed lines: counts from transects bisecting farms
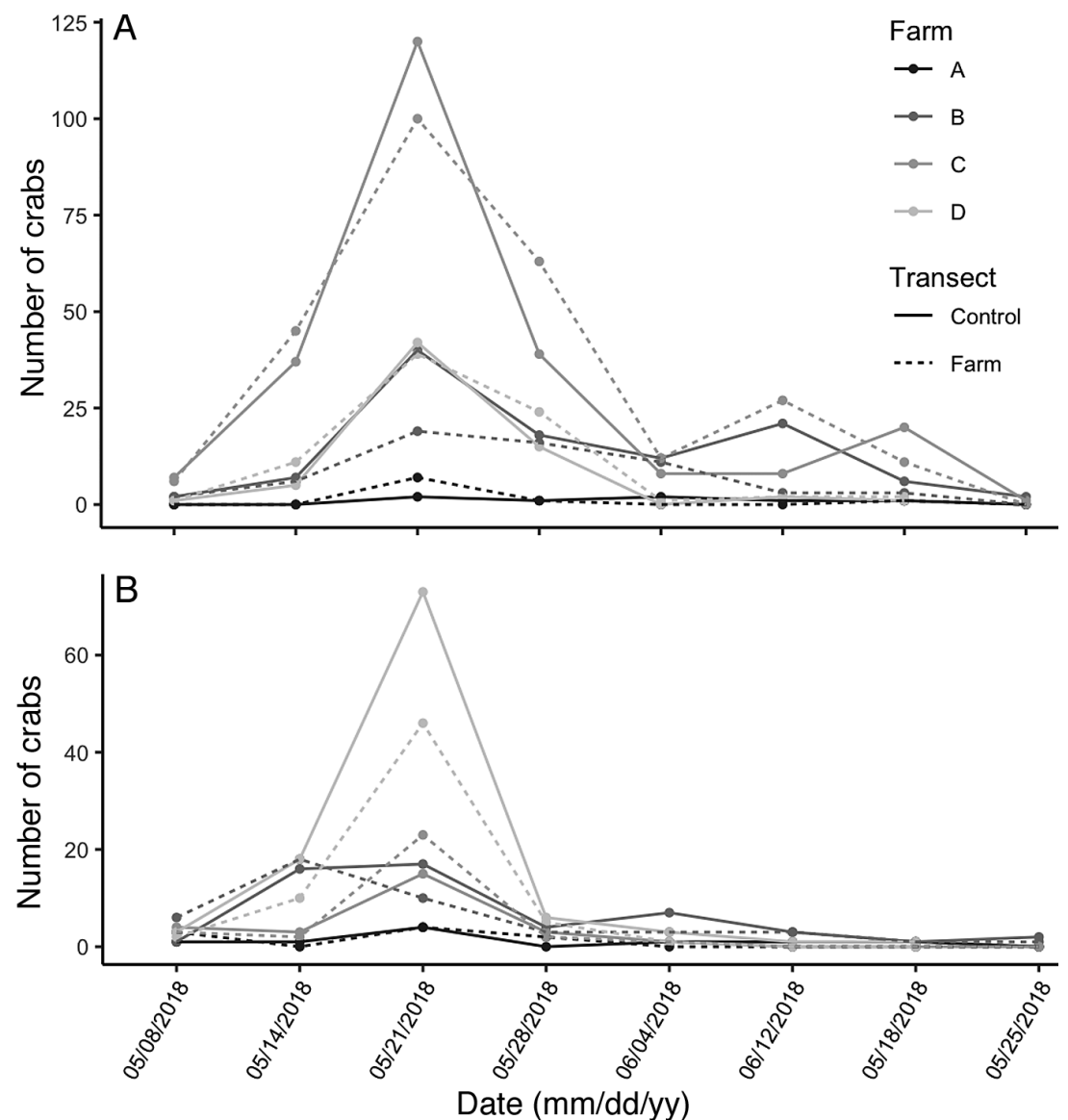
at habitat within the farm footprint compared to controls $(p=0.45)$. Thus, we accept the null hypothesis of no difference in the number of horseshoe crabs observed inshore of, and within, farm gear among paired farm and control transects during low tide.

\subsection{Horseshoe crab survey: high tide}

Transect surveys performed during high tide using sonar showed large aggregations of crabs in sloughs (muddy depressions) closest to the beach slope and sparsely distributed crabs moving independently of other crabs outside of sloughs. On many occasions, horseshoe crabs were observed to move under and out from farm gear unimpeded (examples provided in the Supplement). The number of horseshoe crabs observed during high tide along transects varied depending on the day of observation, the farm, and whether counts were inshore of the farm gear versus within the farm gear. No difference in the number of single horseshoe crabs $(p=0.54)$ or pairs in amplexus ( $p=0.53$ ) was observed between areas inshore of control and farm habitats. Within the footprint of the farm gear, no difference was detected among control and farm counts made for single or amplexus crabs, regardless of corrections for farm gear obstruction (all p > 0.13). Thus, we accept the null hypothesis of no difference in the number of horseshoe crabs observed inshore of, and within, farm gear between paired farm and control habitats during high tide.

\section{DISCUSSION}

Experiments and surveys conducted during the horseshoe crab spawning season in 2018 and 2019 tested the interactions of horseshoe crabs transiting through oyster farms en route to inshore spawning habitat and determined if the oyster farming gear presented a barrier to horseshoe crabs reaching beaches to spawn. Across all of the experiments and surveys, our results indicate that horseshoe crabs can successfully traverse farms and reach spawning beaches, and that horseshoe crabs interact with gear. While this interaction affects some aspects of movement to pass around or traverse through gear, horseshoe crabs successfully transit farms to reach spawning beaches, and crabs do not avoid rack-and-bag farm gear when accessing spawning beaches. These results agree with those of Munroe et al. (2017) and provide important context for developing frameworks for ecological interactions among shellfish farms and wildlife species of concern, particularly with respect to changes in abundance of horseshoe crabs or their behavior due to the presence of oyster rack-and-bag farm gear.

Mature horseshoe crabs ranging in size and including single male and female crabs as well as pairs in amplexus were observed to move beneath, over, and around oyster racks ranging in height from 7.5 to $30.5 \mathrm{~cm}$ off the bottom and over gear placed directly on the bottom. This agrees with preliminary experiments conducted in 2016 - in which only male crabs were tested - that suggested oyster racks with clearance $>10 \mathrm{~cm}$ off bottom do not restrict crab movement (Munroe et al. 2017). Likewise, sonar data collected during high tide at farm and control locations documented crabs (both single crabs and pairs in amplexus) moving unimpeded among farm gear during day and night conditions. Surveys of the habitat inshore of farms showed that crabs are able to access these areas similarly, whether bordered by farm or control habitat, suggesting that the presence of intertidal oyster farms does not impede horseshoe crabs from accessing spawning beaches.

Horseshoe crabs followed a path that covered $3 \%$ more distance as they moved through the rack-andbag farms, likely due to the need to occasionally navigate around or over certain farm structures. Considering a horseshoe crab passing through the maximum farm footprint in this study (287 $\mathrm{m}$; Table 1), an additional $8.6 \mathrm{~m}$ would be required to traverse the farm. Horseshoe crabs are known to make migrations in excess of $100 \mathrm{~km}$ (Swan 2005), making the meterscale $3 \%$ deviation through oyster farms very small in comparison. Regardless, their path is relatively straight (NGDR $=0.89$ at farms, 0.92 at controls) compared to other animals (e.g. 0.45 to 0.72 in salmon, Heerhartz \& Toft 2015; 0.2 to 0.4 in harvester ants, Frizzi 2018; 0.55 to 0.60 in humpback whales, Stanistreet et al. 2013). This strongly directional movement paralleling tidal flow is consistent with previous findings about horseshoe crab movement as they migrate to and from spawning beaches (Rudloe \& Herrnkind 1976, Rudloe 1980). Likewise, the speed over the bottom observed in our sonar study (11 to $14 \mathrm{~cm} \mathrm{~s}^{-1}$ ) is consistent with speeds reported previously (Rudloe 1980). The consistency of the results observed at shellfish farms with those presented previously at other locations suggests that the horseshoe crabs in this study, while traversing or avoiding gear, were otherwise demonstrating normal behavior.

When sonar transect counts of horseshoe crabs within farm sites were corrected for obstruction of the view of the bottom (which should be considered a 
high-end estimate of the number of horseshoe crabs present), there may be slightly more crabs moving within farms at high tide compared to control sites without gear, again confirming results of previous visual-only surveys (Munroe et al. 2017). Oyster farms create complex 3-D structures that can act as habitat for fish, decapods, and other species (Callier et al. 2018). Oyster cages and floating bags may attract and aggregate fish and invertebrates typically associated with natural structured environments (van der Schatte Olivier et al. 2020). It is possible that horseshoe crabs also find oyster farm gear attractive due to increased foraging opportunities, shelter, or other cues; future research may address this possibility.

The concept of conservation aquaculture highlights the important contributions that shellfish farms and other forms of aquaculture can make in achieving local and global conservation goals (Froehlich et al. 2017). When evaluating aquaculture impacts and interactions with wildlife, it is important to establish appropriate reference sites at which to compare wildlife movement and abundance to farms and collect data on potential differences in behavior and reproductive capacity for wildlife at farm sites (Barrett et al. 2019). In this study, we documented changes in horseshoe crab movement and spawning-related habitat use due to the presence of oyster farm gear. Our results, and those of Munroe et al. (2017), suggest that horseshoe crab spawning is not impeded by the presence of rackand-bag oyster farms on the intertidal flats adjacent to spawning beaches, providing an example of the successful coexistence of wildlife with oyster farms.

Acknowledgements. We are grateful for the continued cooperation of the oyster farmers of Delaware Bay and to the tireless field team: M. Acquafredda, J. Barr, D. Bushek, E. Bochenek, J. Bopp, S. Borsetti, I. Burt, R. Cacece, J. Caracappa, L. Calvo, N. Deck, M. Deluca, J. Gius, R. Jarrett, T. Lin, E. Manuel, E. McGurk, J. Morson, J. O'Brien, M. Sclafani, J. Shinn, and M. Zitter. This research was partially supported by Cape May County, by the USDA National Institute of Food and Agriculture Hatch project accession number 1020831 through the New Jersey Agricultural Experiment Station, Hatch project NJ32140, and undergraduate participation was supported by the National Science Foundation under Grant No. OCE-1757499: REU Site: Research Internships in Ocean Sciences (RIOS). This publication is the result of research sponsored by the New Jersey Sea Grant Consortium (NJSGC) with funds from the National Oceanic and Atmospheric Administration (NOAA) Office of Sea Grant, US Department of Commerce, under NOAA grant number NA18OAR4170087 and the NJSGC. The statements, findings, conclusions, and recommendations are those of the authors and do not necessarily reflect the views of the NJSGC or the US Department of Commerce. NJSG publication number 19948. Finally, we thank 3 anonymous reviewers for their thoughtful comments that greatly improved the manuscript.

\section{LITERATURE CITED}

Able KW, Grothues TM, Rackovan JL, Buderman FE (2014) Application of mobile dual-frequency identification sonar (DIDSON) to fish in estuarine habitats. Northeast Nat (Steuben) 21:192-209

*Barrett LT, Swearer SE, Dempster T (2019) Impacts of marine and freshwater aquaculture on wildlife: a global meta analysis. Rev Aquacult 11:1022-1044

* Billing SL (2018) Using public comments to gauge social licence to operate for finfish aquaculture: lessons from Scotland. Ocean Coast Manage 165:401-415

Botton ML (2009) The ecological importance of horseshoe crabs in estuarine and coastal communities: a review and speculative summary. In: Tanacredi J, Botton M, Smith D (eds) Biology and conservation of horseshoe crabs. Springer, Boston, MA, p 45-64

Callier MD, Byron CJ, Bengtson DA, Cranford PL and others (2018) Attraction and repulsion of mobile wild organisms to finfish and shellfish aquaculture: a review. Rev Aquacult 10:924-949

Calvo LM (2018) New Jersey shellfish aquaculture situation and outlook report: 2016 production year. Haskin Shellfish Research Laboratory, Port Norris, NJ. https:// hsrl.rutgers.edu/outreach/aquaculture/Aquaculture Reports/NJAquaculture_Survey_Yr2016.pdf (accessed 1 Dec 2018)

Castro G, Myers JP (1993) Shorebird predation on eggs of horseshoe crabs during spring stopover on Delaware Bay. Auk 110:927-930

Dumbauld BR, Ruesink JL, Rumrill SS (2009) The ecological role of bivalve shellfish aquaculture in the estuarine environment: a review with application to oyster and clam culture in the West Coast (USA) estuaries. Aquaculture 290:196-223

FAO (2018) The state of world fisheries and aquaculture 2018: meeting the sustainable development goals. FAO, Rome

Ford SE, Haskin HH (1982) History and epizootiology of Haplosporidium nelsoni (MSX), an oyster pathogen in Delaware Bay, 1957-1980. J Invertebr Pathol 40:118-141

Frizzi F (2018) Complexity of searching movement in the European harvester ant Messor wasmanni: effect of temperature and body size. Insectes Soc 65:263-273

Froehlich HE, Gentry RR, Halpern BS (2017) Conservation aquaculture: shifting the narrative and paradigm of aquaculture's role in resource management. Biol Conserv 215:162-168

Heerhartz SM, Toft JD (2015) Movement patterns and feeding behavior of juvenile salmon (Oncorhynchus spp.) along armored and unarmored estuarine shorelines. Environ Biol Fishes 98:1501-1511

* Hilborn R, Banobi J, Hall SJ, Pucylowski T, Walsworth TE (2018) The environmental cost of animal source foods. Front Ecol Environ 16:329-335

Koo TK, Li MY (2016) A guideline of selecting and reporting intraclass correlation coefficients for reliability research. J Chiropr Med 15:155-163

* McSweeney JM, Chant RJ, Wilkin JL, Sommerfield CK (2017) Suspended-sediment impacts on light-limited productivity in the Delaware estuary. Estuar Coasts 40:977-993

Meyer D, Zeileis A, Hornik K, Gerber F, Friendly M (2017) vcd: visualizing categorical data. R package version 1.4-4. https://cran.r-project.org/web/packages/vcd/vcd.pdf

Munroe D, Bushek D, Woodruff P, Calvo L (2017) Intertidal 
rack-and-bag oyster farms have limited interaction with horseshoe crab activity in New Jersey, USA. Aquacult Environ Interact 9:205-211

National Marine Fisheries Service (2018) Fisheries of the United States, 2017 report. US Department of Commerce, NOAA Current Fishery Statistics No. 2017. www.fisheries. noaa.gov/resource/document/fisheries-united-states2017-report

Newell RIE (2004) Ecosystem influences of natural and cultivated populations of suspension-feeding bivalve molluscs: a review. J Shellfish Res 23:51-61

Novitsky TJ (2009) Biomedical applications of Limulus amebocyte lysate. In: Tanacredi JT, Botton ML, Smith DR (eds) Biology and conservation of horseshoe crabs. Springer, New York, NY, p 315-329

Price CS, Keane E, Morin D, Vaccaro C, Bean D, Morris JA (2017) Protected species and marine aquaculture interactions. NOAA Tech Memo NOS NCCOS 211

Rose JM, Bricker SB, Ferreira JG (2015) Comparative analysis of modeled nitrogen removal by shellfish farms. Mar Pollut Bull 91:185-190

Rudloe A (1980) Orientation by horseshoe crabs, Limulus polyphemus, in a wave tank. Mar Behav Physiol 7: 199-211

Rudloe A, Herrnkind WF (1976) Orientation of Limulus polyphemus in the vicinity of breeding beaches. Mar Behav Physiol 4:75-89

Editorial responsibility: Pablo Arechavala-Lopez,

Esporles, Illes Balears, Spain
Shuster CN Jr, Botton ML (1985) A contribution to the population biology of horseshoe crabs, Limulus polyphemus (L.), in Delaware Bay. Estuaries 8:363-372

Smith DR, Michels SF (2006) Seeing the elephant: importance of spatial and temporal coverage in a large- scale volunteer-based program to monitor horseshoe crabs. Fisheries 31:485-491

Smith DR, Pooler PS, Loveland RE, Botton ML, Michels SF, Weber RG, Carter DB (2002) Horseshoe crab (Limulns polyphemus) reproductive activity on Delaware Bay beaches: interactions with beach characteristics. J Coast Res 18:730-740

Stanistreet JE, Risch D, Van Parijs SM (2013) Passive acoustic tracking of singing humpback whales (Megaptera novaeangliae) on a Northwest Atlantic feeding ground. PLOS ONE 8:e61263

* Swan BL (2005) Migrations of adult horseshoe crabs, Limulus polyphemus, in the Middle Atlantic Bight: a 17-year tagging study. Estuaries 28:28-40

*USDA (United States Department of Agriculture) (2019) 2017 Census of agriculture. US summary and state data AC-17-A-51. https://www.nass.usda.gov/Publications/ AgCensus/2017/

*van der Schatte Olivier A, Jones L, Vay LL, Christie M, Wilson J, Malham SK (2020) A global review of the ecosystem services provided by bivalve aquaculture. Rev Aquacult 12:3-25

Submitted: October 18, 2019; Accepted: January 24, 2020 Proofs received from author(s): February 17, 2020 